\title{
Ki-67 Antigen Retrieval in Formalin- or Ethanol-fixed, Paraffin-embedded Tissues: An Enhancement Method for Immunohistochemical Staining with Autoclave Treatment
}

\author{
Yoshiro Tsuji ${ }^{1,2}$, Katsuyuki Kusuzaki ${ }^{1}$, Yasusuke Hirasawa ${ }^{1}$, Massimo Serra ${ }^{3}$ \\ and Nicola Baldini ${ }^{3}$ \\ ${ }^{1}$ Department of Orthopaedic Surgery, Kyoto Prefectural University of Medicine, Kyoto 602, ${ }^{2}$ Department of \\ Orthopaedic Surgery, Yokaichi National Hospital, Shiga 527 and ${ }^{3}$ Department of Research Oncology, \\ Rizzoli Orthopaedic Institute, Bologna, Italy \\ Received for publication March 19, 1997
}

\begin{abstract}
We developed a new immunohistochemical method to visualize Ki-67 antigen in formalinfixed, paraffin-embedded sections of bone tumors. The method uses autoclave pretreatment of sections immersed in citrate buffer before incubation with the MIB 1 antibody, which reacts with the Ki-67 gene product. MIB 1 antibody showed strong and
\end{abstract}

discrete staining of cell nuclei in proliferating tumor cells. This method also retrieved antigen in paraffin-embedded sections of alcohol-fixed tissue. Therefore, tissues previously considered unsuitable for immunohistochemical analysis can be studied after autoclave treatment.

Key words: Immunohistochemistry, MIB1 antibody, Autoclave treatment

\section{Introduction}

Progress in immunohistochemical procedures has led to the development of highly specific stains of great value in diagnosis and investigation. Some antigens, however, are difficult to detect by established methods, having lost immunoreactivity because of fixation and paraffin embedding. Previous studies have tried unsuccessfully to resolve this problem using protease digestion to expose antigenic sites blocked by formalin-induced protein cross-linkages [5].

Shi et al. have shown that microwave-oven heating of tissue sections in the presence of metal solutions can retrieve many antigens without enzyme predigestion of tissue. Although the mechanism of microwave antigen recovery is not clear, cross-linking of proteins by formalin may be altered by microwave heating [7]. Shin previously reported that high temperature pretreatment accomplished retrieval of masked antigen [8]. In this study, we

Selected by "The 10th International Congress of Histochemistry and Cytochemistry" held in Kyoto, Japan on Aug. 18-23, 1996.

Correspondence to: Yoshiro Tsuji, M.D., The Department of Orthopaedic Surgery, Yokaichi National Hospital, Yokaichi, Shiga 527, Japan.

Present address: The Department of Orthopaedic Surgery, Yokaichi National Hospital, 255 Gochicho, Yokaichi, Shiga 527, Japan. attempted to retrieve $\mathrm{Ki}-67$ antigen in giant cell tumor of bone using autoclave treatment.

\section{Materials and Methods}

Specimens were obtained from a giant cell tumor of bone occurring in the femur of a 20-year-old woman. This tumor had immunocytochemically revealed $14 \%$ positivity for Ki-67 antigen using fresh tumor tissue. For immunohistochemical study of paraffin-embedded tissue, the specimens were fixed with $10 \%$ buffered formalin $(F)$ or $70 \%$ ethanol (E) for 3 days, decalcified with $5 \%$ ethylenediaminetetra-acetic acid (EDTA)-0.1 M cacodylate buffer ( $\mathrm{pH}$ 7.4) for 7 days, and embedded in paraffin blocks. The sections were cut at a thickness of $4 \mu \mathrm{m}$ and stretched on glass slides coated with poly-l lysine (Sigma, St. Louis, Mo). The slides were deparaffinized and then rehydrated to water. Endogenous peroxidase was blocked with $1 \% \mathrm{H}_{2} \mathrm{O}_{2}$ in methanol for $30 \mathrm{~min}$. The slides were washed with distilled water for $5 \mathrm{~min}$, placed in glass Coplin jars containing $10 \mathrm{mM}$ citrate buffer $(10 \mathrm{mM}$ citric acid monohydrate, pH 6.0 adjusted with $2 \mathrm{~N} \mathrm{NaOH}$ ), and divided into three groups. Group 1 was stained with a conventional avidin-biotin complex $(\mathrm{ABC})$ method, group 2 was pretreated with autoclave heating $\left(100^{\circ} \mathrm{C}, 5 \mathrm{~min}\right)$ and group 3 was pretreated with autoclave heating $\left(120^{\circ} \mathrm{C}\right.$, $5 \mathrm{~min}$ ) before incubation with MIB 1 antibody (D.B.A. 

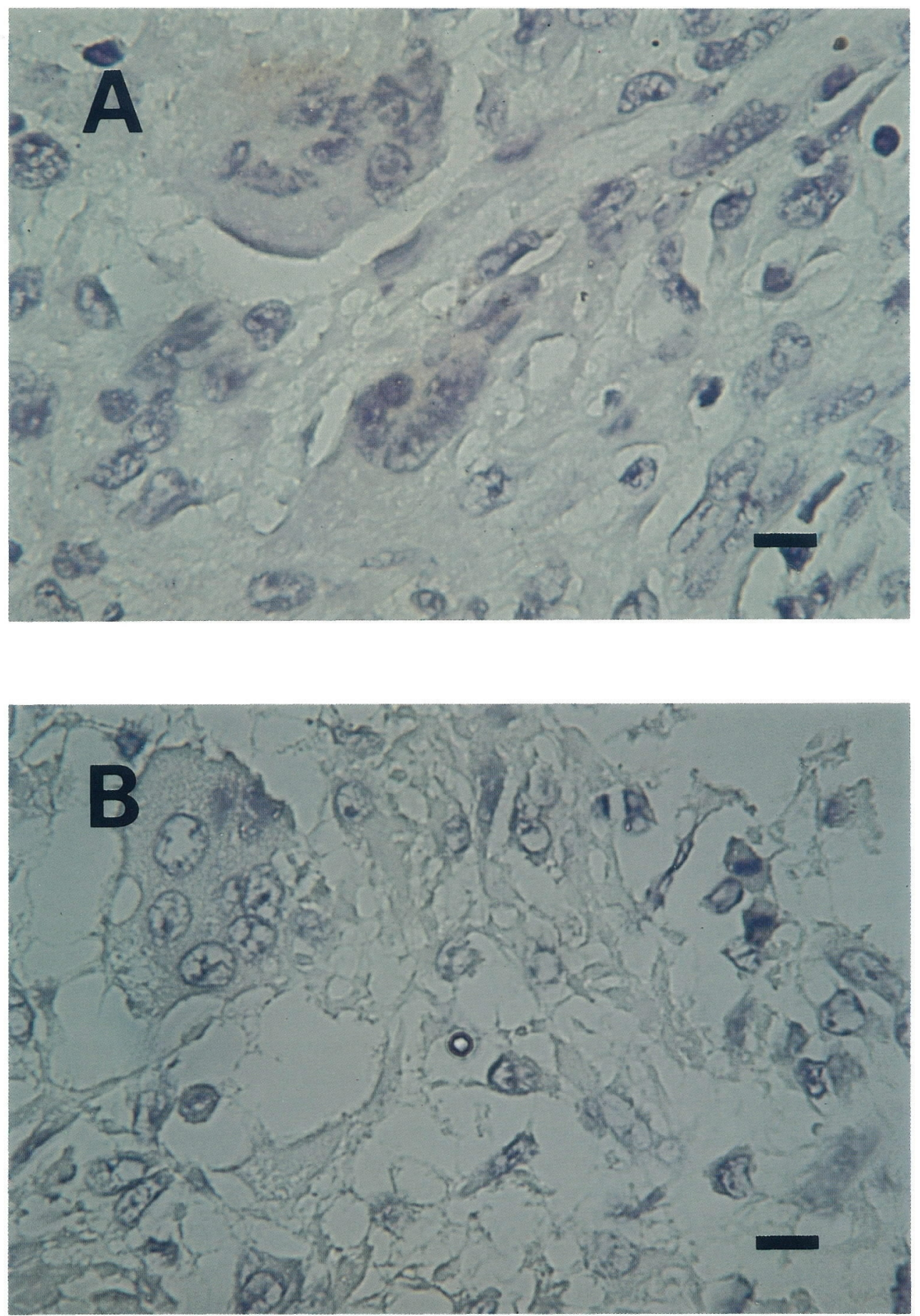

Fig. 1-A, B

Fig. 1. Immunohistochemical stainning of Ki-67 antigen in a case of human giant cell tumor of bone. The specimen was fixed with $10 \%$ buffered formalin (A, C, E) or 70\% ethanol (B, D, F). A, B: Sections stained by a conventional ABC method. Neither mononuclear cells nor multinucleate tumor cells were stained with MIB 1 antibody. $\times 200$. C, D: Sections treated with autoclave heating at $100^{\circ} \mathrm{C}$ for 5 min. $\times 200$. E, F: Sections treated with autoclave heating at $120^{\circ} \mathrm{C}$ for $5 \mathrm{~min} . \quad \times 200$. Bar $=10 \mu \mathrm{m}$; same for Fig. $1 \mathrm{~A}-\mathrm{F}$. 
ITALIA, Milano). After heating, the Coplin jars were allowed to cool in the autoclave until the temperature reached to $50^{\circ} \mathrm{C}$, and then were removed. The Coplin jars were allowed to cool for $30 \mathrm{~min}$. Slides were incubated overnight at $4^{\circ} \mathrm{C}$ with MIB 1 antibody at a concentration of $2.67 \mu \mathrm{g} / \mathrm{ml}$. Sites of antibody-antigen reaction were visualized by treating the sections successively with biotinylated anti-mouse IgG antibody (Dakopatts, Denmark) at $1: 300$ for $30 \mathrm{~min}$, streptavidin-biotinylated peroxidase complex (Dakopatts) at $1: 50$ for $30 \mathrm{~min}$, and finally 3,3'-diaminobenzidine tetrahydrochloride solution in the presence of $\mathrm{H}_{2} \mathrm{O}_{2}$, prior to counterstaining with hematoxylin.
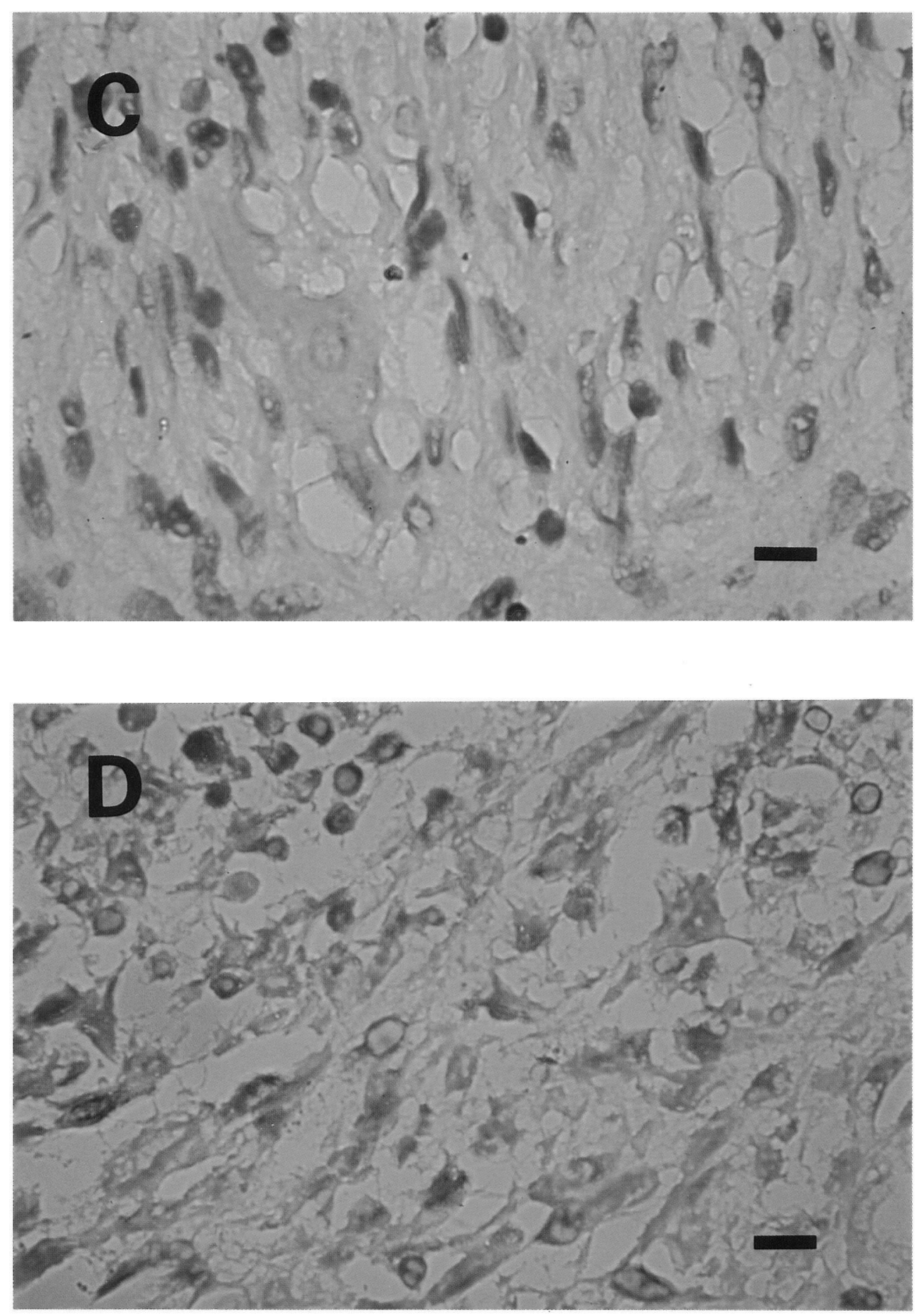

Fig. 1-C, D 


\section{Results}

None of multinucleated cells in any group stained for MIB 1 antibody (Fig. 1). In immunohistochemical staining of group 1, no tumor cells with single nuclei were stained with MIB 1. In group $2 \mathrm{~F}, 9.4 \%$ of mononuclear tumor cells showed nuclear staining, and $10.4 \%$ of such cells in group 2E stained with MIB 1 (Fig. 1-C, D). In group $3 \mathrm{~F}, 15 \%$ of cells were stained, as were $19.7 \%$ of cells in group 3E (Fig. 1-E, F and Fig. 2). However, specimens fixed with $70 \%$ ethanol revealed vacuoles in the nuclei. after autoclave treatment (Fig. 3).
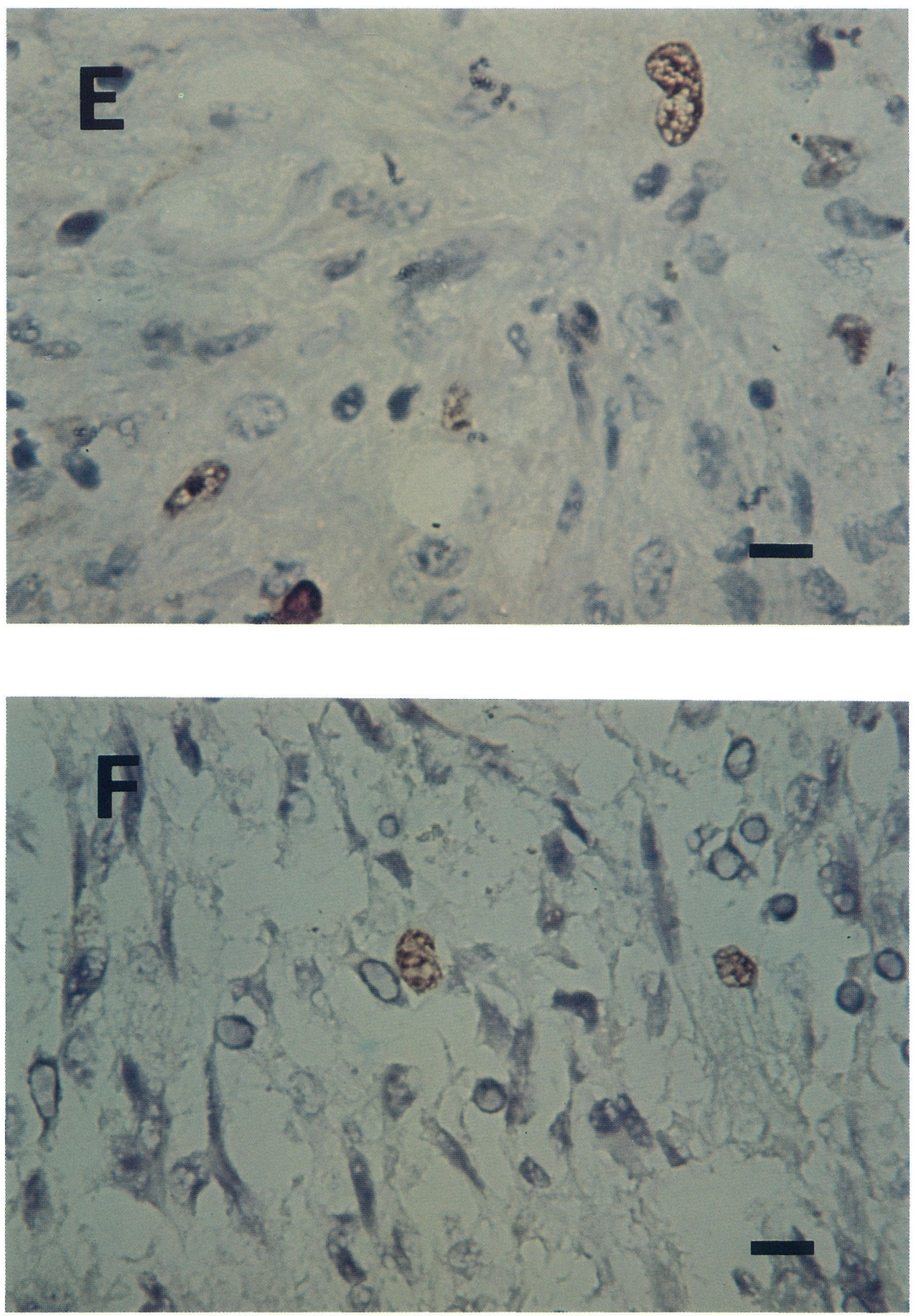

Fig. 1-E, F 
(\%)

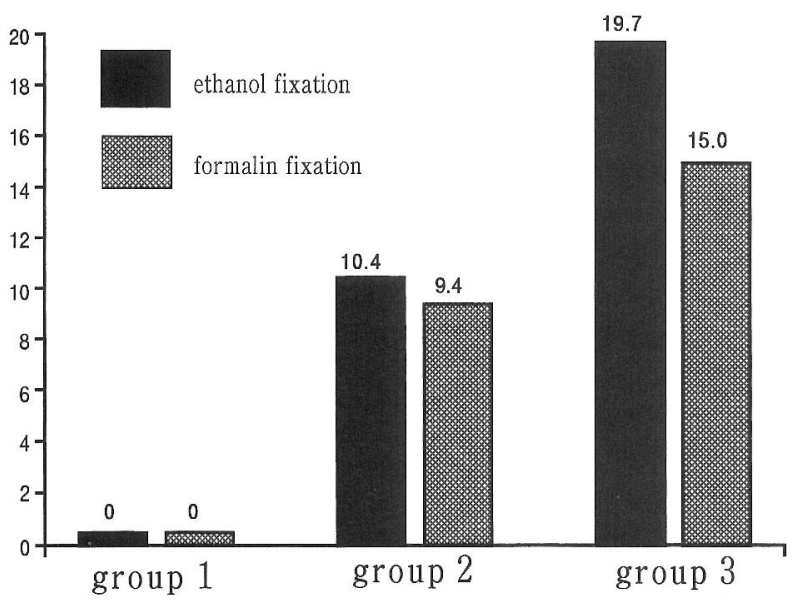

Fig. 2. Percentages of MIB 1-positive cells, by fixation and pretreatment.

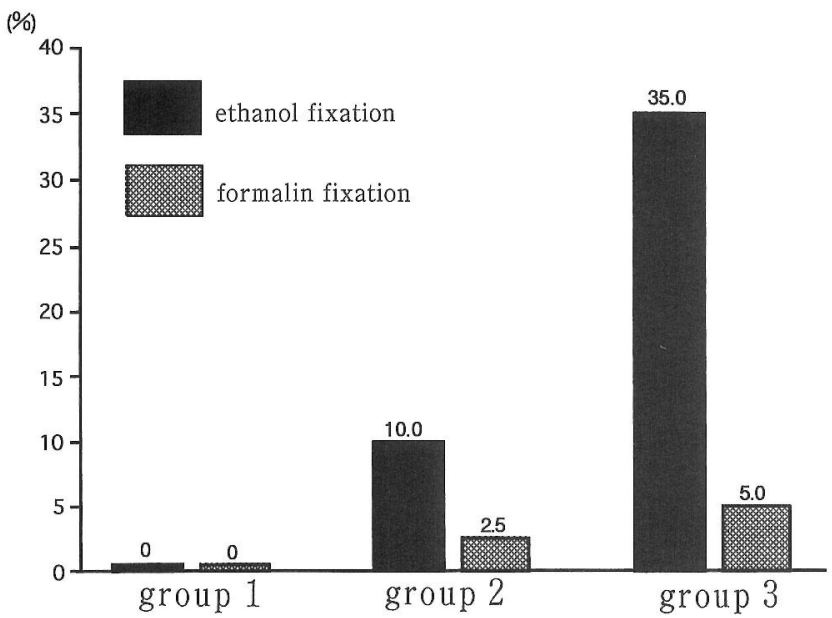

Fig. 3. Percentages of vacuolated cells, by fixation and pretreatment.

\section{Discussion}

$\mathrm{Ki}-67$ is a monoclonal mouse antibody which has been shown to react with a nuclear antigen in proliferating cells $[3,4]$. Numerous studies have found the Ki-67 labeling index to be prognostically relevant in human tumors $[1,2]$. However, routine use of Ki-67 has only involved fresh tissue, since Ki-67 antigen is masked by fixation and paraffin enbedding. Key et al. have raised a new monoclonal antibody, designated MIB 1, by immunizing mice with recombinant $\mathrm{Ki}-67$ gene product. They reported that after paraffin sections immersed in metal salt solutions were heated in a microwave oven, MIB 1 showed strong and discrete staining of proliferating cell nuclei in lymph nodes [6]. Shin et al. reported that autoclave treatment retrieved antigen clearly [8]. In this study, we attempted to retrieve Ki-67 antigen in giant cell tumor of bone using autoclave treatment.

The results we obtained indicated that Ki-67 antigen was retrieved by autoclave treatment, even in these decalcified specimens. Positivity for Ki-67 antigen was increased in group $3 \mathrm{E}$ and $3 \mathrm{~F}$ over the less strongly heated group $2 \mathrm{E}$ and $2 \mathrm{~F}$ (Figs. 1, 2). However, the higher temperature also produced more damage in specimens, especially when fixed with ethanol (Fig. 3). Although the mechanism concerning autoclave recovery of antigen is not clear, heat itself may be important since the higher temperature produced stronger retrieval.

The method described in this report is simple, and has the advantages of little background staining and enhanced laboratory safety since the immersion solution does not contain metal salts such as lead.

These results showed that autoclaving can expand possibilities for retrieval of masked antigen, promising to salvage tissues previously considered unsuitable for immunohistochemical analysis. This method reduces the incidence of false-negative staining, enhancing diagnostic accuracy.

\section{References}

1. Bilous, A.M., Mckay, M. and Milliken, J.: A comparison between Ki-67 antibody reactivity and other pathological variables in breast carcinoma. Pathol. 23; 282-285, 1991.

2. Freedman, A.S. and Nadler, L. M.: Immunologic markers in non-Hodgkin's lymphoma. Hemato. Onco. Clin. North America 5; 871-889, 1991.

3. Gerdes, J., Lelle, R. J., Pickartz, H., Heidenreich, W., Schwarting, R., Kurtsiefer, L., Stauch, G. and Stein, H.: Growth fractions in breast cancers determined in situ with monoclonal antibody Ki-67. J. Clin. Pathol. 39; 977-980, 1986.

4. Gerdes, J., Schwab, U., Lemke, H. and Stein, H.: Production of a human nuclear antigen associated with cell proliferation. Int. J. Cancer 31; 13-20, 1983.

5. Huang, S. N., Minassian, H. and More, J. D.: Application of immunofluorescent staining on paraffin sections improved by trypsin digestion. Lab. Invest. 35; 383-390, 1976.

6. Key, G., Becker, M. H. G., Baron, B., Duchrow, M., Schluter, C., Flad, H. -D. and Gerdes, J.: New Ki-67-equivalent murine monoclonal antibodies (MIB 1-3) generated against bacterially expressed parts of the Ki-67 cDNA containing Three 62 base pair repetitive elements encoding for the Ki-67 epitope. $L a b$. Invest. 68; 629-636, 1993.

7. Shi, S. -R., Key, M.E. and Kalra, K. L.: Antigen retrieval in formalin-fixed, paraffin-embedded tissues. J. Histochem. Cytochem. 39; 741-748, 1991.

8. Shin, R.W., Iwaki, T., Kitamoto, T. and Tateishi, J.: Hydrated autoclave pretreatment enhances TAU immunoreactivity in formalin-fixed normal and Alzheimer's disease brain tissues. Lab. Invest. 64; 693-702, 1991. 